\title{
Dexmedetomidine Hydrochloride
}

National Cancer Institute

\section{Source}

National Cancer Institute. Dexmedetomidine Hydrochloride. NCI Thesaurus. Code C72738.

The hydrochloride salt form of dexmedetomidine, an imidazole derivate and active $d$ isomer of medetomidine with analgesic, anxiolytic and sedative activities.

Dexmedetomidine selectively binds to and activates presynaptic alpha-2 adrenoceptors located in the brain, thereby inhibiting the release of norepinephrine from synaptic vesicles. This leads to an inhibition of postsynaptic activation of adrenoceptors, which inhibits sympathetic activity, thereby leading to analgesia, sedation and anxiolysis. 